\title{
Trichoodontoonychial dysplasia
}

INSERM

\section{Source}

INSERM. (1999). Orphanet: an online rare disease and orphan drug data base.

Trichoodontoonychial dysplasia. ORPHA:3355

Trichoodontoonychial dysplasia is a rare ectodermal dysplasia syndrome characterized by severe generalized hypotrichosis, parietal alopecia, secondary anodontia resulting from enamel hypoplasia, onychodystrophy, bone deficiency in the frontoparietal region and skin manifestations (incl. nevus pigmentosus, papules, ephelides, palmoplantar keratosis, supernumerary nipples, abnormal dermatoglyphics). There have been no further descriptions in the literature since 1983. 